International Journal of Engineering \& Technology, 7 (3.20) (2018) 114-118
International Journal of Engineering \& Technology
WPC
Website: www.sciencepubco.com/index.php/IET
Research paper

\title{
Reducing Ship Queuing Time in Port Operation: A Modelling and Simulation Approach
}

\author{
${ }^{1}$ Fazeeda Binti Mohamad , ${ }^{2}$ Nurul Shahadah Binti Osman Mydin and ${ }^{3}$ Ahmad, A.N.Aizat \\ ${ }^{12}$ Faculty of Industrial Management, Universiti Malaysia Pahang, Malaysia \\ ${ }^{3}$ Faculty of Technology Management and Business (Department of Production Operation) University Tun Hussein Onn, Malaysia \\ Corresponding Author Email: fazeedamohamad@ump.edu.my
}

\begin{abstract}
This study focuses on reducing queuing time in port operation by using discrete event simulation approach. This study was conducted to analyze the port operation activity in order to improve their performance in terms of time operation. A model was developed and simulated by mimicking the real port operation system using a case study. Two scenarios were experimented to see the effects or improvements in the queuing time of container loading and unloading activities. The result demonstrates the positive improvement on the queuing time for container to be loading and unloading.
\end{abstract}

Keywords: Queuing time, Simulation, ARENA software, Container loading and unloading, TEUs

\section{Introduction}

Recently, ports experienced considerable growth especially related to container terminal. It is a significant transition point in the shipping industry. Competitiveness is an important factor for container terminals at ports with an increase in the number of port terminals worldwide. Ship processing time at the container terminal is one of the important factors that affects the attractiveness of terminal ports. The main challenge for most port terminals is the reduction of queuing time with improved facilities.

Ship processing time is crucial as it create competitiveness among the port terminal operators it affected the queuing time in the port operation [25]. The waiting time and queue time in the berthing area is one of the biggest challenges faced by the port manager. Longer waiting time will affect the port terminal efficiency thus will create lower operating service quality as well as reduce operation performance. By increasing the service quality at the port container terminal, the rate of efficiency at the port terminal can be increased.

Port management at the port container needs to focus at the port output rate which has an effect on port terminal productivity. Port terminal waiting time is

one of the aspect that port customer and ship management are concerned. The different types of queuing are considered and included in the ship waiting time at port container terminals. Ships that have arrive at the port terminals should wait for availability at the berthing area. When the berth is available, the ship should wait for the Tug/Pilot machine for tugging to the particular berth.

The discussion on improving the port terminal waiting time has been investigated by[8]. It was among the first research investigating on the queuing system in port terminal. The optimum number of berthing resources and equipment were considered as the installation cost of these resources at berth area of port container terminals. In addition, the queuing system at port terminal also found that the optimum number of berths considered the ship waiting time at berthing area and the idle time of berth equipment [13]. Zarnic et al. (1999) investigated ship waiting time at port container terminals and tried to reduce this time by increasing berth availability and cargo handling capacity.

\section{Literature Review}

In the past, issues related to the queuing problem in the service sector with references to system output have been focused by many researches. Most researchers analysed about this queuing time system according to the ship arrival and departure time. The manager's main goal at port container terminals is increasing port efficiency and reducing the ship waiting time in an effective way. Their concern is to reduce excess capacity at the berth area of port container terminals. Furthermore, researchers also had proposed some ideas to increase port terminal capacity by increasing the amount of the resources. The queuing problem at the port terminal and reduce ship waiting time at berth areas was found to be solved by increasing the number of cranes.

Nowadays, improving the port operation performance by using simulation is becoming popular method for port operation studies. [6] studies a port modelling simulation with optimization capability of operational and economic performance measures. Next, simulated the freight traffic at Sevilla inland port was studied by Cortes et al. (2004). [32] developed a computer simulation model of container movement. Additionally, [31] proposed an alternative approach in simulation for modelling of large maritime infrastructure system. [3] studies about knowledgebased simulation and evaluated the performance of bunkering services at port of Kaohsiung. This studies show that the studies in simulation are very wide in port terminals. [24] developed an 
object - oriented programming approach for a Geographic Information System (GIS) data-driven simulation model of traffic on an inland.

\section{Simulation}

Simulation is used to carry out this project by building the model to mimic the real port operation system. Simulation model have entities, attributes, variables, resources, queues, events, simulation clock and starting and stopping (Kelton, Sadowski et al. 2012). This study uses Arena 13.9 to designed to provide a general purpose collection of modelling features for all types of applications which is first released in 1993. This simulation models can be done by using manually or computer systems and most researcher used a simulation models in experimental techniques.

Simulation is one of the analysis tool that had proven as a costsaving tool to the company. On other hand, the simulation also could assist a user to make quick and reliable decision. Experimenting with real system can be very costly if using simulation that operation can apply like in a real system. The

simulation model is use to mimic the port operations system before apply it at the real port operation. This simulations model gave some equation throughout means and time dependent behaviour that have been determine. Other than that, there are two ways that simulation model could be used for which is analysis tool and design tool. Prediction of effect change that may be occur through the existing system is an analysis tools whereas predict the performance of the new system under a set of circumstances which vary is a design tools.

\section{Methodology}

This study focuses on reducing the queuing time of containe loading and unloading at port terminals. This study was conducted at one port terminal which located in North part of Malaysia. Simulation is known as the popular tool in to analyse and understand a system. It mimics the real operation system to provide more understanding about any system which refers to port terminals system under this study. The capability of modelling entire system and complex interrelationship is a key advantages of modelling and simulation.

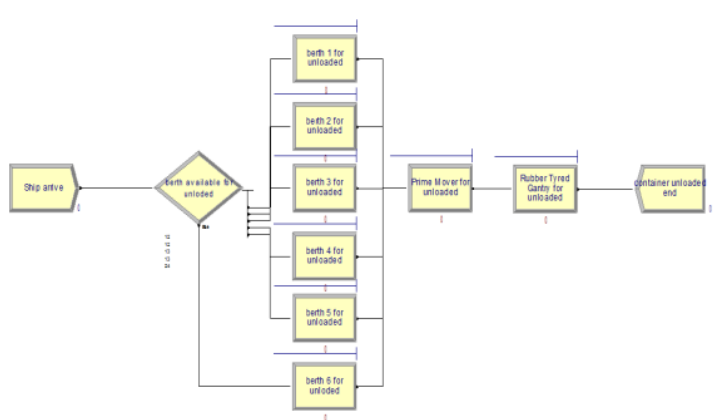

Figure 1.2: Unloading Process In Port Operation

Decision making affected all process that based on the model, whether a model represent the real system is accurate and its result are correct. This aspect was the most important aspect in simulation modelling. This study uses face validity and Mean Absolute Percentage Error (MAPE). The MAPE formula shown was adopted from [27].
Simulation provides flexible which is required for capturing complex process. The real world systems are too complex and expensive and it is impossible to interrupt and experimenting in a real operation system. The complexity of a system can be modelled and experimented as well as enable low cost scenario testing to make inferences about how the actual system might behave. This study uses Arena Software for modelling and simulation. It is one of the leading simulation modelling packages in the world and has a strong and active user base [22].

\section{Model Development}

The process flow of queuing time at the port terminal started from ships arrival at the port until the ship leaves the port terminal. There are several processes that need to be followed after the ships arrival. The efficiency of a container depends on the speed that the container can be served at the port. Port performance which refers the efficiency under this study depends on the quick service of container loading and unloading.

Container loading and unloading are very important to obtain an efficient port performance. A real port terminal is modelled and simulated. Problem solving that arises simultaneously at several levels in port terminal is possible by using simulation. Minimising the queuing time of container loading and unloading from the ship arrival at the port terminal until the ships leave the port terminal is the main objective. The complete path which container go through from the ship to the container yard by using prime mover is model by using simulation.

This study can provide an assessment of the operations by using simulation software. The actual modelling of queuing time in simulation software can be different as what we want. Thus, the understanding is needed for advanced models and to identify where the problem lies.

\section{Validation and Verification of the Model}

The verification and validation of computer simulation model were directly amid the improvement of a simulation model. It is proven with a definite objective of delivered an exact and trustworthy model.

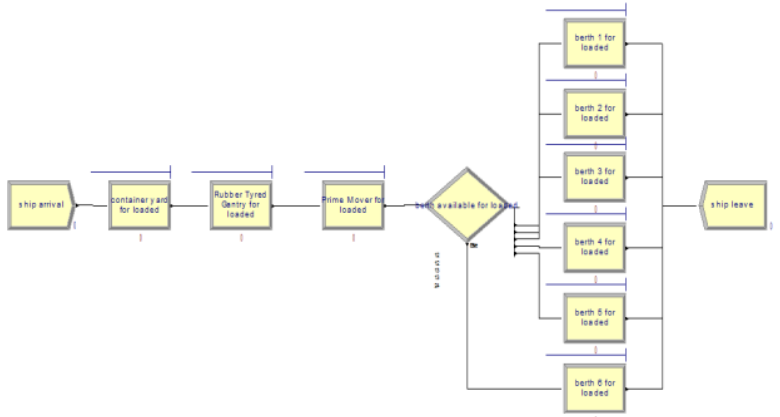

Figure 1.1: Loading process in Port Operation 


\section{Explanation:}

$X m=$ forecast value

$X d=$ actual data

Testing the accuracy of the model is accurate or not by using Mean Absolute Percentage Error (MAPE) will have some conditions which is:

1) The model can be defined as accurate with respect to the real system if MAPE value is $<5 \%$.

2) The model can be considered as accurate model if MAPE value is between 5\% until $10 \%$.

3) The model can be considered not accurate and need to rebuild if the MAPE value is $>10 \%$.

Calculated MAPE value to validate the model for this study shown as below:

$$
\begin{aligned}
\text { MAPE } & =\Sigma \frac{|90-88|}{88} \times 100 \% \\
& =2.27 \%
\end{aligned}
$$

\section{Scenario Analysis}

\subsection{Base Case: the Actual Simulation at the Port Terminal}

This was the actual scenario that happened at the port terminal. This simulation model had been run for four hours by choosing the busy hours for loading and unloading the container. The average for container loading and unloading were 22 TEUs of containers per hours. Therefore, the container could be loading and unloading for four hours is 88 TEUs. The total container had been improved to 90 TEUs of containers.

On the other hand, 30 replications with 90 entities had been run by the model. The replication refers to the days of the port operation.
The highest queuing time recorded for container loading and unloading

was at the Prime Mover (PM) which was 37.3336 minutes. The lowest queuing time recorded for container loading and unloading which was 2.2690 at berth 4 . Queuing time was the most time consuming phases based on the real situation. "What if" analysis is used to improve the performance based on few scenarios.

\subsection{Scenario 1: Use all the Prime Mover}

Using 'what if' analysis by ensuring all the prime mover have been used to move the container from quay gantry crane to rubber tired gantry for unloading processed and from container yard to ship for loading processed. According to the interviewed session with the port manager and staff, the port under study did not use all the prime mover due to less worker and maintenance of prime mover. This scenario has been created to shorten the time for queue and improving the output of the container. The port can only unload and load the container at average of 88 to 90 TEUs in 4 hours. By using the simulation, the performance of container loading and unloading has been improved to 95 TEUs equivalent to $5.5 \%$ improvement. The average queuing time of container loading and unloading has also improved by a reduction of $0.6 \%$ from 37.3336 to 37.0976 minutes.

\subsection{Scenario 2: Adding one more Quay Gantry Crane at berth 5}

The second scenario for this study is by adding one more Quay Gantry Crane (QGC) at the berth 5 since the stated berth loading activities is the highest. Thus, by adding one more QGC can fastened the process of loading and unloading of container. The container loading and unloading has been improved from 95 to 102 TEUs of container. The result shows the improvement number of containers loading and unloading by adding one more QGC at the berth 5. The details of the scenarios result can be referred as in Table 2.1 .

Table 2.1: The base case result and improvement from different scenarios

\begin{tabular}{|l|c|c|c|c|c|}
\hline \multicolumn{1}{|c|}{ Activity } & Base case & Scenario 1 & $\begin{array}{c}\text { Improvement } \\
\mathbf{( \% )}\end{array}$ & Scenarios 2 & $\begin{array}{c}\text { Improvement } \\
\text { (\%) }\end{array}$ \\
\hline Berth 1 & 2.6021 & 1.9730 & 24.1766 & 0.2290 & 91.1994 \\
\hline Berth 2 & 3.7815 & 2.5332 & 33.0107 & 0.2530 & 93.3095 \\
\hline Berth 3 & 3.8640 & 1.4045 & 63.6517 & 0.0643 & 98.3359 \\
\hline Berth 4 & 2.2690 & 1.5980 & 29.5725 & 0.1555 & 93.1468 \\
\hline Berth 5 & 12.0980 & 6.9529 & 42.5285 & 3.0077 & 75.1388 \\
\hline Berth 6 & 6.5327 & 6.1827 & 5.3577 & 5.0975 & 21.9694 \\
\hline Prime mover & 37.3336 & 37.0976 & 0.6321 & 25.1635 & 32.5982 \\
\hline Rubber Tyred Gantry & 23.5609 & 18.2567 & 22.5127 & 21.4015 & 9.1652 \\
\hline Output & 90 & 95 & 5.5556 & 102 & 13.3333 \\
\hline
\end{tabular}




\section{Conclusion and Recommendation}

[10] Hunecker, F. (2013). A generic process simulation-model for educational simulations and serious games. On the Horizon, 17(4), 313-322. doi:10.1108/10748120910998371

Time for an object involves in a system to get a service before leaving the system is known as a queuing time. Researchers have found the importance to reduce queuing time as a way to improve the operation performance. It was found that the biggest issue related to port operations in this study is the queuing time of containers to be loading and unloading. This is due to certain problems such as bad weather (heavy rain and strong wind), equipment breakdown, system down (signal for radio set down) and agent or vessel problem.

Modelling and simulation used under this study shows significant impacts in terms of the improvement in the port operation performance. It was found that the time for containers handling is improved by the increased numbers of TEUs handled. It also shows that a modelling and simulation has the capacity to run the models in order to help the managers better see their operations. Improvement in the queuing time of container loading and unloading provides many positive impact to the port such as the efficiency of the port performance, no overtime needed as well as the reputation of the port will be increased. The port is advised to do the maintenance at least once a month to quay gantry crane (QGC), rubber tired gantry (RTG) and prime mover (PM) to avoid equipment breakdown. Next, the profitability of the Port under study will be increased as they do not have to pay the overtime for their workers.

\section{Acknowledgement}

The authors would like to thank Universiti Malaysia Pahang for the grant provided (RDU1603132) as well as to the ports management for their cooperation during the data collection and until the completion of this study.

\section{References}

[1] Alessandri, A., Sacone, S., \& Siri, S. (2006). Modelling and Optimal Receding-horizon Control of Maritime Container Terminals. J Math Model Algor, 6(1), 109-133. doi:10.1007/s10852-006-9052-3

[2] Bruzzone, A. G. (1998). Harbour and Maritime Simulation. SIMULATION, 71(2), 72-73. doi:10.1177/003754979807100201

[3] Chang, Y., \& Chen, C. (2006). Knowledge-based simulation of bunkering services in the port of Kaohsiung. Civil Engineering and Environmental Systems, 23(1), 21-34. doi:10.1080/10286600600585625

[4] Chen, E. J., \& Kelton, W. D. (2007). A Procedure for Generating Batch-Means Confidence Intervals for Simulation: Checking Independence and Normality. SIMULATION, 83(10), 683-694. doi:10.1177/0037549707086039

[5] Cortés, P., Muñuzuri, J., Nicolás Ibáñez, J., \& Guadix, J. (2004). Simulation of freight traffic in the Seville inland port. Simulation Modelling Practice and Theory, 15(3), 256271. doi:10.1016/j.simpat.2006.11.004

[6] Dahal, K., Galloway, S., Burt, G., Mcdonald, J., \& Hopkins, I. (2003). A Port System Simulation Facility with An Optimization Capability. Int. J. Comp. Intel. Appl, 03(04), 395410. doi:10.1142/s1469026803001099

[7] De Swaan Arons, H., \& Van Asperen, E. (n.d.). Computer assistance for model definition. 2000 Winter Simulation Conference Proceedings (Cat. No.00CH37165). doi:10.1109/wsc.2000.899745

[8] Edmond, E. D., \& Maggs, R. P. (1978). How Useful are Queue Models in Port Investment Decisions for Container Berths? J Oper Res Soc, 29(8), 741-750. doi:10.1057/jors.1978.162

[9] Goobie, G., \& Arbez, G. (2013). The Modelling and Simulation Process. Modelling and Simulation, 19-51. doi:10.1007/978-14471-2783-3_2
[11] J.J. Shields. (1984). Container Stowage: A computer aided preplanning system Marine Technology, 21(4).

[12] K.H. Kim. (2004). Deriving decision rules to locate export containers in container yards, 124(2000), 89-101.

[13] Kia, M. P. (1992). Minimize Cost of Berthing (Port of Engineers, Australia, 92(8), 231-237.

[14] Kim, K. H., \& Park, Y. (2004). A crane scheduling method for port container terminals.European Journal of Operational Research, 156(3), 752-768. doi:10.1016/s0377-2217(03)001334

[15] Krajewski, L. J., \& Ritzman, L. P. (2002). Operations Management: Strategy and Analysis (2nd Edition). The Journal of the Operational Research Society, 43(4), 367. doi: $10.2307 / 2583162$

[16] Law, A. M. (2008). How to build valid and credible simulation models. 2008 Winter Simulation Conference. doi:10.1109/wsc.2008.4736054

[17] Legato, P., \& Mazza, R. M. (2001). Berth planning and resources optimisation at a container terminal via discrete event simulation. European Journal of Operational Research,133(3), 537-547. doi:10.1016/s0377-2217(00)00200-9

[18] Maria, A. (1997). Introduction to modeling and simulation. Proceedings of the 29th conference on Winter simulation - WSC '97. doi:10.1145/268437.268440

[19] Maria, A. (1997). Introduction to modelling and simulation. Proceedings of the 29th conference on Winter simulation - WSC '97. doi:10.1145/268437.268440

[20] Martagan, T. G., Eksioglu, B., Eksioglu, S. D., \& Greenwood, A. G. (2009). A simulation model of port operations during crisis conditions. Proceedings of the 2009 Winter Simulation Conference (WSC). doi:10.1109/wsc.2009.5429245

[21] Ranau, M. (2011). Planning Approach for Dimensioning of Automated Traffic Areas at Seaport Container Terminals. Operations Research/Computer Science Interfaces Series, 179-193. doi:10.1007/978-1-4419-8408-1_10

[23] Sacone, S., \& Siri, S. (2009). An integrated simulationoptimization framework for the operational planning of seaport container terminals. Mathematical and Computer Modelling of doi:10.1080/13873950902808636

[24] Sasso, D., \& Biles, W. E. (2008). An object-oriented programming approach for a GIS data-driven simulation model of traffic on an inland waterway. 2008 Winter Simulation Conference. doi:10.1109/wsc.2008.4736372

[25] Shahpanah, A., S. Shariatmadari, Ali Chegeni, A. Gholamkhasi, and M. Shahpanah. 2014. "Improvement in Queuing Network Model to Reduce Waiting Time at Berthing Area of Port Container Terminal via Discrete Event Simulation", Applied Mechanics and Materials

[26] Schriber, T. J., Brunner, D. T., \& Smith, J. S. (2013). Inside discrete-event simulation software: How it works and why it matters. 2013 Winter Simulations Conference (WSC). doi:10.1109/wsc.2013.6721439

[27] Somantri, A. S., \& Thahir, R. (2007). Dynamic system analysis of rice availability in Merauke. Dynamic System Analysis of Rice Availability in Merauke, 3.

[28] Steenken, D. (2004). Container terminal operation and operations research - a classification and literature review. OR Spectrum, 26(1), 3-49. doi:10.1007/s00291-003-0157-z

[29] Steenken, D., Voß, S., \& Stahlbock, R. (n.d.). Container terminal operation and operations research - a classification and literature review. Container Terminals and Automated Transport Systems, 3-49. doi:10.1007/3-540-26686-0_1

[30] UMEDA, S., \& JONES, A. (1999). A Simulation-Based BPR Support System for Supply Chain Management. The Quest for World-Class Excellence, 95-117. doi:10.1142/9781848160576 0006

[31] Valentin, E., Steijaert, S., Bijlsma, R., \& Silva, P. (n.d.). Approach for Modeling of Large Maritime Infrastructure Systems. Proceedings of the Winter Simulation Conference, 2005. doi:10.1109/wsc.2005.1574426 Melbourne). National Conference Publication -Institution of

[22] Rossetti D. (2010). Simulation Modelling and ARENA, 2-3. Dynamical Systems, 15(3), 275-293. 
[32] Van Rensburg, J., Yi He, \& Kleywegt, A. (n.d.). A Computer Simulation Model of Container Movement by Sea. Proceedings of the Winter Simulation Conference, 2005. doi:10.1109/wsc.2005.1574424

[33] Vis, I. F., \& De Koster, R. (2003). Transshipment of containers at a container terminal: An overview. European Journal of Operational Research, 147(1), 1-16. doi:10.1016/s03772217(02)00293-x

[34] Wilson, I. D., \& Roach, P. A. (2000). Container Stowage Planning: A Methodology for Generating Computerised Solutions. The Journal of the Operational Research Society,51(11), 1248. doi:10.2307/254210

[35] Worldshipping, (2012). (Accessed 17.03.13). (n.d.). . Retrieved from (Accessed 17.03.13)

[36] Yang, C. H., Choi, Y. S., \& Ha, T. Y. (2004). Simulation-based performance evaluation of transport vehicles at automated container terminals. OR Spectrum, 26(2), 149-170. doi:10.1007/s00291-003-0151-5

[37] Zrnić, D. N., Dragović, B. M., \& Radmilović, Z. R. (1999). Anchorage-Ship-Berth Link as Multiple Server Queuing System. J. Waterway, Port, Coastal, Ocean Eng, 125(5), 232240. doi:10.1061/(asce)0733-950x(1999)125:5(232). 